\title{
Editorials
}

\section{Board activities and actions}

The following summary reviews activities and actions taken by the Editorial Board of the Annals over the last year.

A large volume of interesting material is received by the Annals, requiring sound selection by our expert review panel; we are grateful for their detailed work in this area. The main thrust of the journal remains innovative clinical papers from across all surgical disciplines. Inter- and multi-disciplinary studies are particularly appropriate for our large multispecialty readership.

Although welcomed, well-controlled clinical trials are difficult to achieve in the surgical field. However, much progress is achieved by subtle changes in management, and these readers need to know about. Results based on unique information that are fully documented and carry a cogent message are thus encouraged.

The board intends to publish more guidelines from NICE and other sources, when these are available.

Individual case histories are well subscribed and Jerry Kirk carries the heavy load of their initial assessment. The high rejection rate is a reflection on the limited space available, rather than their standard, and the board is keen to expand this section as a web-based option. While enthusiastically welcoming David Atkins, our new publication's manager, we draw your attention to his article below: it outlines the current status of this project.

Ingenta, our web developer, exposes the journal to a potential audience of 25 million and gives readers access to over 2000 publications. Nevertheless, it is disappointing that these facilities are only used by a small number of fellows, members and affiliates. Access requires Athens authentication, and this may be the limiting factor. Thalia Knight, our librarian, has written Bulletin articles on the subject and further details are on the College web site (see below), we will continue to promote this approach.

Lack of computer know-how may also be the reason why the Web-based chatrooms and discussion boards are not yet winners; we will persist in our mission to ensure that the whole fellowship benefits from these facilities.

Overseas fellows are an important part of our readership and in forthcoming issues we will be examining how their particular needs can be met, as well as educating all readers in tropical issues.
New sections introduced last year have established themselves as a valuable part of the Annals. Bruce Campbell's Technical section, with its tutorials and tips, has become the focus for all surgical technical matters in the journal; it has stimulated debate and alternate views often spill over into the Letter's section. Abstracts brought together by Linda de Cossart recognise the best trainee presentations in meetings from across the country - the Editorial Board has agreed to fast tracking the assessment of full papers arising from these abstracts. Nick Cheshire's web watch provides a valuable distillation of articles and entry points into the chosen topics - sadly we currently can only include a limited number each year. John Lowry edits the Faculty columns of the Bulletin and also identifies book reviewers - we again thank these and all our review panels.

The Bulletin communicates news and is a vehicle for fellows, members and affiliates to air their views on controversial issues (a number do exist!), and all opinions are welcomed. They include the new contract, EWTD, the loss of continuity of care, the emphasis on teamwork, clinical targets, increasing specialisation, management of the generality of surgery, separation of emergency and elective practice and the College's own strategy concerning communication and regionalisation.

Training also deserves full debate, with the introduction of the PMETB, specialist needs and seamless training, under the backdrop of reduced working hours and new curricula. Tom Dehn is to edit sections on alternative approaches in these areas and debatable clinical issues in the Annals; we are particularly looking for letters and articles suggesting constructive solutions. The Trainee's Forum editorial team is also keen to receive opinions from across the whole spectrum of surgery.

Finally, I extend my sincere thanks, and that of the readership, to all the Board and editorial staff, for the expert and responsible way they give of their skills to deliver this important part of the College's fabric.

John Lumley Editor 


\section{The journal}

$T_{b}$ he online versions of the Annals and Bulletin have now been live for over a year; while the discussion forums proved to be something of a failure, the number of users accessing the site has increased month-by-month reaching nearly 3500 visitors in October. Hopefully, this increasing trend will continue as the number of issues available rises and searching will produce more meaningful results across a wider data set.

Another advantage of online access, apart from the ease of searching, is our membership of CrossRef and other linking organisations as this allows the reader to click the active links in the reference list and be taken directly to the paper's abstract. So no more having to return to the library to locate yet another journal.

An exciting service our developers are offering is forward linking; this identifies other papers, hosted on their servers, that cite the current article you are browsing, which if you are reviewing your own article will be of particular interest. The profile of this service will be raised the more issues of the Annals and Bulletin that appear online.

All papers appearing in the Annals are indexed in NLM's PubMed database making your article available to the widest possible audience. Access is free to all those who receive the printed Annals and Bulletin. Details of how to activate your online access, via an Athens username and password, can be found on the Publications section of the College's website <http://www.rcseng.ac.uk/services/ publications $/>$.

Following a prolonged period of investigation, it looks as though we will be able to go-ahead with posting onlineonly case reports on the Annals' website. As you are aware, we have to decline more papers than we accept for publication because of the limitations of space within the printed version of Annals and the ever-increasing number of papers we receive. Next year, we hope to launch this new service with your papers being citable, and assigned a URL and a DOI; thus, details of the link can be passed to your colleagues, and quoted in reference lists and in the preparation of funding applications.

The editorial team are currently in discussion with a number of aggregators and abstracting and indexing services, to include the header data from the Annals and Bulletin in their databases once again opening your papers out to a wider audience.

We are delighted to announce that the Annals and Bulletin have linked up with the WHO-sponsored HINARI initiative <http://www.healthinternetwork.net/>. HINARI is designed to give online access either free, or at a greatlyreduced cost, to institutions in countries that would otherwise find the charges prohibitive and excluding them from the huge pool of knowledge contained within these learned publications. This service is supplied by the WHO, in partnership with major STM publishing companies, to provide access to over 2200 scientific and medical journals.

A service provided by the College, whilst not directly applicable to the readers of the Annals and Bulletin, is one you will find useful when preparing material for publication. We are hosting an image database of a small selection of the photographs collected by College photographers over the years <http://www.slipstreamonline.co.uk/RCS/>. You can browse images for use, for a fee, in your articles, papers and publications. The big advantage this service offers is that all permissions to use the images have already been acquired; all you need to do is order online and a high-resolution version of the image will be despatched to you.

David Atkins Publications Manager

\section{EDITORIAL BOARD}

Editor: John Lumley

Assistant Editors

Bruce Campbell, Nick Cheshire, Linda de Cossart, John Lowry

Section Editor: Matt Revell

Members

Tan Arumpalam, Thomas Dehn, Charlotte Foley, Mark Hartley, Jerry Kirk, Neil Kitchen, Jeremy Taylor, Andrew Unwin, Ian Weir, Mark Whiteley 